\title{
UNA CRÍTICA A UN CRÍTICO DEL «NO POSITIVISMO». A PROPÓSITO DE «LA TESIS DEL CASO ESPECIAL Y EL POSITIVISMO JURÍIICO», DE ALFONSO GARCÍA FIGUEROA
}

Isabel Lifante Vidal

Universidad de Alicante

\section{Introducción}

En el artículo «La tesis del caso especial y el positivismo jurídico», Alfonso García Figueroa pretende defender el «positivismo jurídico» y los logros metodológicos implícitos en él frente a una concepción del Derecho con cierto predicamento en los últimos años y que supondría una revisión de los postulados positivistas. Esta corriente se conoce con etiquetas muy diversas; utilizaré aquí la de «no positivismo» por ser la empleada por García Figueroa. Su estrategia consiste en utilizar, como eje para articular sus críticas, la tesis -cada vez más extendida- de que el razonamiento jurídico es un caso especial del razonamiento práctico general: la llamada «tesis del caso especial» ${ }^{1}$. Mi objetivo aquí es utilizar el análisis de este concreto artículo como excusa para ocuparme de la concepción del Derecho que subyace a estas críticas al «no positivismo». La elección de este trabajo de García Figueroa como representativo de esa concepción del Derecho se justifica porque, en mi opinión, en él se recogen de manera particularmente clara y bien articulada la mayoría de los argumentos que se utilizan en contra de las concepciones del Derecho rivales: las «no positivistas» $\mathrm{o}$ «postpositivistas». Mi objetivo no es entrar a discutir si los rótulos son usados adecuadamente en esta polémica, ni precisar los distintos significados que adquieren los mismos para los distintos autores, y ni siquiera defender las concretas

\footnotetext{
${ }^{1}$ Ahora bien, las concepciones del Derecho a las que se dirigen sus críticas en este artículo son prácticamente las mismas a las que en un trabajo anterior aglutina bajo el rótulo de «no positivismo principialista» (entre las que se incluyen como exponentes destacadas las teorías del Derecho de Dworkin o de Alexy). Me refiero a su libro Principios y positivismo jurídico (García Figueroa, 1998), en el que analiza críticamente la virtualidad concedida a los principios jurídicos y a su creciente protagonismo en el Derecho para desplazar al positivismo jurídico. Su argumentación en este libro, aunque algo más desarrollada, coincide en lo fundamental con la sostenida en el artículo aquí analizado.
} 
teorías «no positivistas» que son objeto de crítica. Lo que pretendo es únicamente analizar la pertinencia de las críticas utilizadas y, al mismo tiempo, poner de manifiesto algunos problemas que en mi opinión existen en la concepción del Derecho que subyace a las mismas.

Recogeré en primer lugar la caracterización del positivismo jurídico y de la tesis del caso especial que García Figueroa toma como punto de partida; a partir de aquí expondré brevemente las críticas que este autor dirige a las teorías que defienden la tesis del caso especial (o, mejor dicho, a algunas versiones de esta tesis) y que se centran en el aspecto tendencialmente antipositivista que presenta esta tesis al reforzar la vinculación conceptual entre Derecho y moral. A continuación señalaré algunos problemas que, en mi opinión, pueden encontrarse en la argumentación en contra de este «desafío» al positivismo. La conclusión que espero que se extraiga de mi planteamiento no es, como he dicho, la defensa de alguna versión de la tesis del caso especial, sino poner de manifiesto algunos errores en la crítica al mismo, y la consideración de que ciertos postulados que se consideran incompatibles con las tesis positivistas no tienen en realidad por qué serlo, o si se quiere, que el «positivismo» (o la concepción del Derecho, en caso de que no se esté de acuerdo en seguir considerándola «positivista») que me parece aceptable no coincide con el presupuesto por García Figueroa.

\section{La defensa del «positivismo jurídico»}

Siguiendo fundamentalmente a Raz, García Figueroa considera que la «esencia» del positivismo jurídico radica en sostener la «tesis de la separación», según la cual no existiría una relación conceptual necesaria entre el Derecho y la moral. Esta tesis se asienta a su vez en otras dos: la tesis de las fuentes sociales del Derecho y la tesis de la falibilidad del Derecho. Según la primera, el Derecho es producto de una serie de prácticas sociales, se trata por tanto de una obra de los hombres; precisamente por ello es falible, y lo es tanto moral como técnicamente. Es moralmente falible porque sus respuestas pueden ser incompatibles con la moral crítica. Esta falibilidad moral es la que se expresa en la segunda tesis, la de la separación entre Derecho y moral: «se puede y se debe establecer los límites que separan las normas jurídicas de las normas morales, los usos sociales, etc.», que sería lo que Raz denomina la «tesis de los límites del Derecho». La falibilidad técnica implicaría que el Derecho no siempre proporciona soluciones a los problemas que se le plantean (puede ser impreciso lingüísticamente y presentar lagunas y antinomias); desde la perspectiva del aplicador del Derecho, esta falibilidad vendría a dar lugar a lo que, siguiendo a Lyons, denomina la «tesis del Derecho limitado». Esta tesis nos lleva normalmente -dice Gar- 
cía Figueroa- a defender la tesis de la discreción judicial que impulsa al juez a buscar la solución en otros órdenes normativos.

Esta concepción del positivismo es relativa al concepto de Derecho, por lo que, en principio -dice García Figueroa-, no debería verse afectada por una tesis como la del caso especial que es relativa a la argumentación e interpretación jurídica. Sin embargo considera que los planteamientos de algunas versiones de esa tesis han intentado desafiar a los presupuestos del positivismo y es precisamente este intento el que es objeto de su crítica. Para exponerla, considera necesario analizar previamente en qué consiste exactamente la tesis del caso especial, ya que la misma adolece de una extremada ambigüedad. En particular, habría dos variables que deben tenerse en cuenta: 1) el carácter descriptivo o normativo de la tesis, y 2) la adscripción del razonamiento práctico general a la moral social o a la moral críti$\mathrm{ca}^{2}$. Conjugando estas variables resultan cuatro distintas versiones de la tesis del caso especial:

a. El razonamiento jurídico es un caso especial de razonamiento moral social.

b. El razonamiento jurídico debe ser un caso especial de razonamiento moral crítico.

c. El razonamiento jurídico es un caso especial de razonamiento moral crítico.

d. El razonamiento jurídico debe ser un caso especial de razonamiento moral social.

En su primera versión, la tesis del caso especial no supone ningún desafío al positivismo jurídico y resultaría incompatible sólo con «un positivismo teórico estricto asociado a una teoría formalista de la interpretación». La segunda versión sería una tesis normativa sobre la argumentación jurídica que prescribe la adecuación del razonamiento jurídico a la razón práctica, y que podría verse como el complemento normativo de la primera versión; aquí se situaría la tesis de MacCormick (al menos en una de sus

${ }^{2}$ En este punto, García Figueroa lleva a cabo una observación sobre qué debe entenderse por «moral social» o «moral crítica», según se adopte el punto de vista interno o externo. En su opinión, desde un punto de vista externo es posible indicar qué significa moral crítica y moral social; sin embargo, desde la perspectiva del participante sólo es posible formular una «moral crítica social» (es decir, el conjunto de pautas aceptadas como correctas por el participante; se trataría por tanto de una moral objetivamente social, pero subjetivamente crítica). «Si el participante formula un juicio moral puramente crítico, entonces está adoptando un punto de vista externo, porque no acepta a priori la moral que evalúa. Si el participante formula un juicio moral puramente social (descriptivo), entonces también está adoptando un punto de vista externo, porque no acepta, sino que sólo describe una serie de prácticas. En ambos casos el participante deja de serlo genuinamente» (García Figueroa, 1999, p. 200). 
posibles interpretaciones ${ }^{3}$ ). La cuarta versión no es considerada relevante, ya que -en opinión de García Figueroa- se limitaría a formular desde una perspectiva externa la teoría de la interpretación que sostendría un participante fuertemente comprometido con la moral positiva; se trataría, por tanto, de la postura de un positivista ideológico.

La tercera es la versión más fuerte de la tesis del caso especial; según ella el razonamiento jurídico queda conceptualmente vinculado al razonamiento moral racional. Ésta sería la versión de la tesis del caso especial defendida por Alexy ${ }^{4}$; para este autor todo acto de habla normativo (y el razonamiento jurídico lo es) presenta una pretensión de corrección. En principio esta pretensión sólo garantizaría la vinculación a la moral social; para vincular el razonamiento jurídico al razonamiento moral racional es necesario adoptar un punto de vista interno, que es precisamente lo que hace Alexy. Desde esta perspectiva, sería de algún modo contradictorio que un agente adoptara unos criterios jurídicos o morales que no fueran considerados por él mismo como correctos. Esta versión de la tesis del caso especial es la que interesa a García Figueroa porque es la que presenta una «especial virtualidad antipositivista» y porque, además, es la que mayor relevancia ha adquirido en los últimos años.

¿En qué consiste la «virtualidad antipositivista» de esta versión de la tesis del caso especial? En opinión de García Figueroa, según la misma, los juristas «hacen justicia según derecho», lo cual implica: 1) que «el juez hace siempre justicia en alguna medida cuando aplica el Derecho» (lo que supondría una moralización del razonamiento jurídico) y 2) que «siempre aplica el Derecho en alguna medida cuanto imparte justicia» (lo que supondría una juridificación del razonamiento moral). La primera afirmación entraría en conflicto con la tesis positivista de la separación entre moral y Derecho, en tanto que presupone con carácter necesario lo que el positivismo

\footnotetext{
${ }^{3}$ García Figueroa señala que la teoría de MacCormick ha sufrido una evolución desplazándose desde esta segunda versión de la tesis del caso especial a la tercera. Este desplazamiento vendría reconocido por el propio MacCormick, quien ha señalado que ha sido convencido por Alexy y Habermas acerca de la vinculación entre la razón práctica discursiva y el razonamiento jurídico, matizándose por tanto sus planteamientos inicialmente positivistas al estilo hartiano.

${ }^{4}$ No estoy segura de que la tesis del caso especial defendida por Alexy se encuentre bien caracterizada en el trabajo de García Figueroa, al menos si tenemos en cuenta las matizaciones que el propio Alexy ha establecido recientemente al defender su tesis frente a las críticas formuladas por Habermas; fundamentalmente la consideración de que el razonamiento práctico general, del que el razonamiento jurídico sería un caso especial, no puede ser identificado sin más con el razonamiento moral (cfr. Alexy, 1999). Sin embargo, voy a dejar esta cuestión al margen, dado que, como ya he dicho, no pretendo defender ni la teoría del Derecho de Alexy, ni una determinada versión de la tesis del caso especial.
} 
considera contingente: cierta corrección moral en las premisas normativas (entre ellas las jurídicas) del razonamiento jurídico (ha de haber al menos un cierto grado de injusticia que ha de quedar excluido). Y la segunda afirmación, la de que el juez aplica el Derecho al impartir justicia, afectaría a la tesis positivistas de los límites del Derecho y, en consecuencia, a la tesis del Derecho limitado y a la tesis de la discreción judicial (pp. 210 y ss.). Veamos por separado los problemas que plantean estas dos afirmaciones.

Respecto a la incompatibilidad con la tesis de la separación entre Derecho y moral, García Figueroa sostiene que la misma podría salvarse apoyándose en alguna de las dos siguientes posibilidades: a) establecer la corrección moral en términos puramente formales, procedimentales; o b) restringir la extensión de los razonamientos jurídicos y limitarla a aquéllos que proporcionan premisas adecuadas para un razonamiento moral correcto. Ambas estrategias son, en su opinión, legítimas, pero se ubicarían en un discurso puramente estipulativo que plantearía los siguientes problemas: desde un metadiscurso analítico, supondría importantes riesgos de confusión e incorporaría cuestiones metaéticas difíciles de resolver (como: ¿qué significa «justicia»?, ¿dónde está el límite de lo justo, lo injusto y lo extremadamente injusto?); desde un metadiscurso normativo, la estipulación no positivista comporta la devaluación de la moral crítica. Esta saludable relativización de la polémica en términos de meras estipulaciones lingüísticas nos debería llevar -dice García Figueroa- al terreno de determinar qué concepto de Derecho es el menos engañoso posible desde un metadiscurso analítico y normativo; y, desde esta perspectiva, considera que el positivismo sigue siendo la mejor opción.

Respecto a la segunda incompatibilidad, provocada por la «juridificación del razonamiento moral», García Figueroa considera que la cuestión fundamental es aquí determinar si realmente «aplica el juez derecho cuando hace justicia», tal y como suponen los partidarios de la tesis del caso especial. En rigor, dice García Figueroa, el juez tiene el deber de aplicar el Derecho y solamente el Derecho. El problema parece ser que en las decisiones judiciales «la riqueza del output no puede ser explicada con tal pobreza de input». Para dar cuenta de ello caben dos interpretaciones: una positivista y otra no. Según el positivismo, el juez aplicaría el Derecho y ejercería además cierta discreción judicial. Al input inicial (el sistema jurídico) se le habrían añadido otros elementos (consideraciones de justicia, referencias a la moral social o condicionamientos ideológicos). Sin embargo, según el no positivismo, el sistema jurídico no sería tan restringido como sostiene el positivismo. Ésta sería la tesis fundamental de Dworkin. Por su parte, Alexy aceptaría esta tesis y consideraría que la misma ha de ser complementada además con la distinción en el Derecho de un lado pasivo (com- 
puesto por una serie de normas: tanto reglas positivistas, como principios dworkinianos) y un lado activo (procedimientos); de manera que el Derecho debe ser contemplado, no meramente como un conjunto estático de normas, sino también como un sistema de procedimientos argumentativos. El resultado, dice García Figueroa, es que la teoría del Derecho tiende a convertirse en una teoría de la argumentación jurídica; y si a esto le añadimos que, según esta versión de la tesis del caso especial, la teoría de la argumentación jurídica tiende a convertirse en una teoría de la argumentación moral, entonces el Derecho tiende a aproximarse a una forma de razonamiento moral. Y de ello no sólo sale perjudicado, dice García Figueroa, el concepto de Derecho, sino que también se desvirtúa la función judicial: «si todo lo que el juez aplica es derecho por el hecho de aplicarlo, entonces el juez no está vinculado por derecho alguno» (p. 217). Estos problemas se basan, en su opinión, en la confusión de las nociones de pertenencia y aplicabilidad, causada por la adopción del punto de vista interno o del participante.

\section{Una crítica a la crítica}

Las críticas que, según acabamos de ver, dirige García Figueroa a la concepción «no positivista» del Derecho implícita tras la tesis del caso especial pueden agruparse atendiendo a su carácter conceptual o ideológico. Corresponderían al primer grupo (las de carácter conceptual) la denuncia de las confusiones entre teoría del Derecho y teoría de la argumentación jurídica, entre teoría de las fuentes y teoría de la aplicación, y entre pertenencia y aplicabilidad. Las críticas de carácter ideológico, que se vinculan a la adopción del punto de vista del participante, implicarían la «contaminación» ideológica de la teoría, generando a su vez la pérdida de virtualidad de la moral para operar como instancia crítica frente al Derecho. Mis observaciones a estas críticas van a seguir el mismo orden expositivo: en primer lugar analizaré los problemas argumentativos que, en mi opinión, pueden encontrarse en las supuestas confusiones conceptuales denunciadas por García Figueroa y a continuación expondré algunas observaciones relacionadas con su denuncia del carácter ideológico de las tesis «no positivistas».

\subsection{Confusiones conceptuales}

Empecemos con los problemas conceptuales. En opinión de García Figueroa, los defensores de la tesis del caso especial (en su tercera versión) confundirían la teoría del Derecho con la teoría de la argumentación, la aplicación, o el método jurídico, y olvidarían la distinción entre pertenencia y aplicabilidad, produciendo así una disolución del concepto de Derecho y de la función judicial. Veamos hasta qué punto estos reproches son merecidos. 


\subsubsection{El ámbito de la «teoría del Derecho»}

Quizás una de las principales objeciones que García Figueroa atribuye a la tesis del caso especial es que tras ella se puede encontrar una confusión entre la teoría del Derecho y la teoría de la argumentación o de la aplicación jurídica. Pero si nos fijamos, se parte de un concepto de «teoría del Derecho» que excluye totalmente cualquier asunto relacionado con la argumentación o aplicación, con lo cual la conclusión parece en principio inatacable: si hemos excluido, por definición, las cuestiones argumentativas o aplicativas del ámbito de la teoría del Derecho, entonces lógicamente dichas cuestiones han de quedar fuera de la misma. Pero la cuestión interesante -y ausente en su análisis- sería la de determinar si, y en su caso por qué, estas cuestiones no han de formar parte de una teoría del Derecho. Si no queremos pecar de esencialistas, habremos de admitir que una buena teoría del Derecho sería aquélla que dé cuenta adecuadamente del fenómeno jurídico: de la práctica y de la doctrina jurídica. En este sentido, y si estamos de acuerdo en considerar que el Derecho es fundamentalmente una técnica de control social, cuya función es la de guiar la conducta de los ciudadanos, creando para ello normas generales que pretenden orientar la conducta de cara al futuro y resolviendo los conflictos que puedan surgir, aplicando para ello esas normas, entonces habremos de admitir que el Derecho está compuesto por dos grandes «momentos»: la creación de normas generales y la aplicación de esas normas para la resolución de casos concretos. Cada uno de esos dos momentos tiene un protagonista fundamental (aunque no exclusivo): el legislador, en el caso de la creación de normas, y el juez, en el de la aplicación. Si esto es así, una buena «teoría del Derecho» será aquélla capaz de dar cuenta adecuadamente de ambos momentos o, al menos, habrá que considerar que esos dos momentos están igualmente legitimados para integrar una teoría del Derecho.

Ahora bien, en el Derecho nos encontramos con dos dimensiones, presentes -aunque con distinta intensidad- en todas sus manifestaciones ${ }^{5}$; me refiero a la dimensión de poder, o voluntarista, y a la dimensión justificativa, o racionalista. Estas dos dimensiones se encuentran entre sí en tensión, de manera que no es fácil (y quizás ni siquiera posible) integrarlas en una reconstrucción unitaria y coherente del fenómeno jurídico. Y es fácil perca-

${ }^{5}$ En este sentido, Aguiló señala, por ejemplo, que la situación normativa de cualquier autoridad jurídica vendría dada por dos factores: por un lado, por la determinación de cuáles son sus poderes; y, por otro lado, por cuáles son sus deberes relativos al ejercicio de esos poderes. Mientras que la primera perspectiva trataría de dar cuenta de los aspectos voluntaristas, la segunda se centraría en los aspectos racionales o justificativos (cfr. Aguiló Regla, 2000, pp. 119 y ss.). 
tarse de que en cada uno de esos dos grandes momentos, o desde la perspectiva de cada uno de esos protagonistas, se acentúa una distinta dimensión del Derecho. Desde el momento creativo, el Derecho se ve fundamentalmente como un fenómeno en el que prima la dimensión de poder (o voluntarista); mientras que desde el momento aplicativo, la dimensión predominante es la justificativa (o racionalista).

La mayoría de las concepciones del Derecho adoptan, a la hora de analizar el fenómeno jurídico, o bien la perspectiva creativa o bien la perspectiva aplicativa, asumiendo como protagonista central del Derecho bien al legislador, bien al juez; y por tanto, caracterizan uno de estos momentos de manera central y el otro de una manera que podríamos considerar «residual». De este modo, las teorías que mejor han dado cuenta del Derecho como orden jurídico, serían las que han adoptado el punto de vista del legislador, pero al precio de presentar una teoría débil respecto al método jurídico. Y, al contrario, las teorías que adoptan la perspectiva del caso, y que serían las que ofrecen las mejores teorías del método jurídico, serían las que presentan problemas para reconstruir el Derecho como orden jurídico (Aguiló, 2000, pp. 182-187). Si ahora nos fijamos en cómo García Figueroa caracteriza expresamente la concepción del Derecho por él suscrita (que claramente se trata de una teoría del Derecho visto como orden jurídico, es decir, desde la perspectiva del legislador), veremos que la misma también incluye -como no podía ser menos- una determinada caracterización de la función aplicadora del Derecho, eso sí, presentada de forma subsidiaria o dependiente de la caracterización que se hace del Derecho visto como orden jurídico. ¿Qué otra cosa es, si no, la tesis de la discreción judicial? Y por el otro lado, la teoría del Derecho que suscriben los partidarios de la tesis del caso especial, en cuanto teoría que asume la perspectiva aplicativa, tendría como objetivo central ofrecer una caracterización del método jurídico, pero al precio de presentar sólo de manera residual una teoría del Derecho como orden jurídico. Esto último sería precisamente lo que podría denunciar García Figueroa frente a la teoría del Derecho que suscriben los partidarios de la tesis del caso especial. Pero lo que en mi opinión no resulta justificado es utilizar la perspectiva adoptada para analizar el fenómeno jurídico como argumento para negar la calidad de «teoría del Derecho» a una determinada concepción.

\subsubsection{La distinción entre pertenencia y aplicabilidad. La caracterización de las fuentes del Derecho y de la adjudicación}

Muy ligada a la crítica anterior, García Figueroa denuncia otra confusión conceptual en la que incurrirían los defensores de la tesis del caso especial: se trata en este caso de no haber tenido en cuenta la distinción, de- 
sarrollada por Bulygin (1991), entre las nociones de pertenencia y aplicabilidad, produciendo así una confusión entre la teoría de las fuentes y la teoría de la adjudicación, de la cual saldría perjudicado no sólo el concepto de Derecho, sino también la caracterización de la función aplicadora del Derecho. Veamos cómo se desarrolla este argumento.

García Figueroa (pp. 217 y ss.) considera que una norma pertenece al Derecho cuando es válida ${ }^{6}$, mientras que una norma aplicable sería aquélla susceptible de aplicación por los jueces. No voy a entrar aquí a determinar cuál es el concepto de «validez», o pertenencia, manejado por García Figueroa, pero creo que resulta claro que se trata de un concepto formal. En palabras de Moreso (y que creo que García Figueroa no tendría problemas en suscribir), el criterio es normalmente el genético o de legalidad, según el cual una norma $N$ pertenece a un sistema jurídico $S J$ si hay otra norma $N^{\prime}$, perteneciente a $S J$ que autoriza a un determinado órgano $O$ la promulgación de $N$ y $O$ promulga $N$. Esta estructura genética depende de la pertenencia a dichos sistemas de normas que confieren poderes. Aunque pertenencia y aplicabilidad suelen coincidir, esto no siempre ocurre. Éste sería el caso, por ejemplo, de las normas extranjeras que resultan aplicables en un determinado Derecho en virtud de una norma de conflicto del Derecho internacional privado. Siguiendo a Moreso, cuyas aportaciones en este punto asume García Figueroa, podría decirse que la aplicabilidad de una norma depende siempre de la existencia de otra norma perteneciente al sistema y que obliga o faculta a aplicarla. Este esquema sería, en opinión de Moreso, útil para explicar no sólo la aplicabilidad de estas normas extranjeras, sino también la de las normas consuetudinarias, la de ciertas normas derogadas, o irregulares, y también el caso de los estándares de moralidad ${ }^{7}$. Obviamente, de entre estas dos nociones, la de pertenencia y la de aplicabilidad, la que goza de primacía para García Figueroa es la de pertenencia, que vendría determinada por criterios formales, ofrecidos por la teoría de las fuentes (entendida ésta en un sentido bastante limitado, como luego veremos), mientras que la de aplicabilidad (en realidad, dependiente de aquélla, e incluso prescindible) sería interesante, en todo caso, para una teoría de la adjudicación $^{8}$ (recordemos aquí la pretensión de García Figueroa de excluir la teoría de la adjudicación del ámbito de la teoría del Derecho).

${ }^{6}$ Cfr. Moreso, 1997, p. 145.

${ }^{7}$ Cfr. Moreso, 1997, pp. 155-160.

${ }^{8}$ Moreso se aparta de esta consideración, al estimar que la noción de aplicabilidad, aunque en algún sentido es dependiente de la pertenencia (puesto que las normas son aplicables o inaplicables en virtud de otras normas que pertenecen a los sistemas jurídicos) sí resulta interesante para la teoría del Derecho (Moreso, 1997, pp. 154-155). 
A partir de aquí, García Figueroa denuncia la injustificada asimetría (fruto en su opinión de la adopción del punto de vista del aceptante) que se ha producido en el tratamiento que los juristas han dado a las distintas normas que, no «perteneciendo» a un determinado Derecho, resultan aplicables según el mismo. Así, mientras que, por ejemplo, las normas de otros Derechos, a cuya aplicabilidad remite una norma de Derecho internacional privado, han sido normalmente consideradas como «extrajurídicas»; por el contrario, es usual considerar que las normas «morales» o estándares del razonamiento práctico general sí que están integrados en el Derecho. En opinión de García Figueroa esta última consideración implica grandes inconvenientes para la caracterización de la función jurisdiccional: «Si todas las normas que figuran en la argumentación de un juez -dice García Figueroadeben ser consideradas parte del derecho, entonces la propia vinculación del juez al derecho dejaría de existir [...] si todo lo que el juez aplica es derecho por el hecho de aplicarlo, entonces el juez no está vinculado por derecho alguno» (p. 217). Pero veamos con mayor detalle la argumentación de este autor.

Hay que ser conscientes de que la definición de pertenencia manejada es claramente estipulativa (pocos juristas considerarían que sólo «pertenecen» al Derecho las normas emanadas de autoridades, dejando fuera los principios implícitos, las normas consuetudinarias...); si situamos, por tanto, su discurso en el ámbito estipulativo, lo que debemos plantearnos es la virtualidad explicativa de estas categorías. Y en este sentido creo que esos dos casos (las normas que se suelen considerar «extrajurídicas» y las que suelen considerarse integradas en el Derecho) no pueden recibir, como propugna este autor, un tratamiento unitario porque son esencialmente distintos y -como voy a intentar mostrar- no creo que la explicación de cómo operan estas normas en el sistema jurídico a partir de esta disociación entre pertenencia y aplicabilidad resulte igualmente aceptable en ambos casos. En el caso de las normas que usualmente se consideran «extrajurídicas» (como las normas de otros ordenamientos jurídicos), la norma «aplicable» no pretende integrarse permanentemente en el sistema jurídico de que se trate, y quizá por ello en este caso sí tenga sentido disociar pertenencia y aplicabilidad de la norma. Piénsese, por ejemplo, en qué pasaría si se modificara una norma de Derecho italiano que resulta aplicable según el Derecho español para regular un determinado caso concreto; creo que sería raro pensar que se ha producido un cambio permanente en el Derecho español. Las normas del Derecho italiano no pretenden ordenar la conducta de la sociedad española. Sin embargo, en el segundo caso, el de los estándares de racionalidad práctica, o de las normas consuetudinarias, sí que se genera la pretensión de integración permanente en el Derecho; así, si se produce un 
cambio en las normas consuetudinarias, o en los estándares de moralidad que se consideran «aplicables» en el Derecho español creo que tendría perfecto sentido sostener que ha habido un cambio en este Derecho. Lo que ocurre en estos casos es, en mi opinión, que no se puede explicar la «integración» de estas normas en el Derecho (o su función en el mismo) atendiendo al expediente de la «pertenencia», precisamente porque se ha tomado como punto de partida una definición de «pertenencia» en términos formales, de modo que sólo puede ser predicada de las «normas jurídicas» entendidas como documentos normativos o disposiciones que pueden verse como resultados institucionales (lo cual no quiere decir que dichas disposiciones no sean portadoras de significado, sino que su identificación se hace teniendo en cuenta exclusivamente el proceso institucional del que el texto es el resultado); es decir, se trata de las normas que son el resultado del uso de reglas que confieren poder. Sin embargo, cuando se habla de las normas consuetudinarias o de los estándares de moralidad, se está utilizando un sentido distinto de «norma», el cual, a diferencia del anterior, no se refiere a una disposición resultado de un proceso institucional y por lo tanto no puede decirse de ellas que «pertenezcan» al sistema en el sentido estipulado. Pero creo que aquí tampoco funcionaría la explicación en términos de «aplicabilidad» tal y como la entiende este autor. Si recordamos, una norma se consideraba «perteneciente» únicamente cuando había sido promulgada por un órgano autorizado para hacerlo por otra norma perteneciente al sistema y la «aplicabilidad» de una norma dependía siempre de la existencia de otra norma «perteneciente» al sistema, que obligaba o facultaba a aplicar aquélla. Pero, en la mayoría de esos casos, no hay manera de explicar la aplicabilidad del concreto estándar moral o de la concreta norma consuetudinaria por una mera referencia a una norma perteneciente al Derecho. Por supuesto que es normal encontrar normas jurídicas «pertenecientes» que remiten a la costumbre como fuente del Derecho, o que contienen alusiones, por ejemplo, a la moral pública; pero estas referencias o alusiones no son suficientes para identificar la concreta norma consuetudinaria o el estándar de moralidad que ha de ser aplicado (y no creo que estemos dispuesto a considerar que cualquier práctica social o cualquier estándar de moralidad, por el mero hecho de serlo, se considere jurídicamente «aplicable»). Y ello sin mencionar que en muchas ocasiones el recurso a estándares de racionalidad práctica se lleva a cabo sin que exista expresamente esa previa llamada de una norma «perteneciente» al sistema.

Con lo visto hasta aquí, es fácil darse cuenta de que García Figueroa trabaja con un concepto de fuentes del Derecho bastante reduccionista. Si consideramos que el problema de la teoría de las fuentes es el de determinar el origen de las normas jurídicas, el objetivo de dicha teoría ha de ser, por tan- 
to, poner en relación las normas jurídicas con los procesos de los que ellas son el resultado. En este sentido las normas podrían clasificarse atendiendo a su origen, es decir, a las fuentes de las que proceden, en las siguientes categorías: normas provenientes de autoridades políticas, normas que provienen de autoridades jurisdiccionales, normas que provienen de ciertas prácticas sociales, y normas que provienen de la elaboración racional del propio Derecho9. Pues bien, de todas estas categorías, las únicas de las que daría cuenta la teoría de las fuentes que parece implícitamente asumida por García Figueroa sería la de las normas provenientes de autoridades políticas. Se trata de un concepto de fuentes que no sólo no puede dar cuenta de las normas que provienen directamente de lo que Aguiló llama la elaboración racional del propio Derecho, cuya aceptación como «fuente del Derecho» sería en el fondo la cuestión que late en su discusión con los representantes de la tesis del caso especial ${ }^{10}$; sino que ni siquiera conseguiría explicar la virtualidad de la costumbre ${ }^{11}$ o de la jurisprudencia como creadoras de normas jurídicas. En todos estos casos para identificar la norma en cuestión es necesario contar con «algo más» que criterios formales o institucionales. Lo que justifica aquí la «incorporación» de esas normas a un determinado Derecho (llamémosle aplicabilidad, pertenencia o como se quiera) sería la idea de coherencia, la unidad de contenidos, lo que implica acudir a procesos ar-

${ }^{9}$ Tomo esta clasificación de Aguiló Regla (2000, p. 67).

${ }^{10}$ Respecto a la función creadora de Derecho de lo que Aguiló (2000, pp. 125 y ss.) llama la elaboración racional del propio Derecho, hay que ser conscientes de que el Derecho así creado (lo que suele considerarse como «Derecho implícito") no es el resultado del ejercicio de ningún poder normativo, sino del uso del método jurídico y por tanto está abierto a todos los que utilizan el Derecho para emitir juicios normativos evaluadores de normas y conductas, es decir en esta tarea creadora o integradora de Derecho pueden participar todos los integrantes de la comunidad jurídica (dogmáticos, juristas prácticos, opinión pública). Incluir en el Derecho las normas provenientes de esta elaboración racional del propio Derecho es lo que nos permite explicar por qué consideramos que cualquier participante en la práctica puede realizar críticas «jurídicas» a decisiones judiciales o a otras conclusiones normativas.

${ }^{11}$ Una adecuada comprensión de la costumbre como fuente jurídica exige, junto a los clásicos elementos material (el usus) y espiritual (la opinio o conciencia de obligatoriedad), un juicio de relevancia jurídica fundado en la idea de coherencia valorativa del Derecho Sin este requisito, no se podría distinguir a las costumbres jurídicas del resto de las reglas sociales. A veces se piensa que basta con la consideración de que la conciencia de obligatoriedad ha de ser «jurídica"; este intento de explicación se habría llevado a cabo mediante dos recursos, ninguno de los cuales resultaría satisfactorio: o bien se considera que el contenido de la opinio ha de ser «jurídica» (pero esto implicaría que el carácter de juridicidad sería anterior e independiente del sistema jurídico y se convertiría en poco menos que tautológico) o bien se considera que los sujetos de esa opinio son los jueces, y que de ahí proviene su juridicidad. Pero este último intento supondría considerar que las normas jurídicas lo son porque los jueces las aplican. Sigo aquí a Aguiló Regla (2000, pp. 92-96), quien a su vez utiliza en este punto el trabajo de Bruno Celano: «Consuetudine e norme sulla produzione di norme», en P. Comanducci y R. Guastini (eds.): Struttura e dinamica dei sistemi giuridici, Giappichelli, Turín, 1996. 
gumentativos (lo que suele conocerse como el «método jurídico»); y esto sólo puede ser adecuadamente «observado» a partir de la dimensión justificativa o racionalista del Derecho a la que antes hacíamos referencia y que, como vimos, queda relegada desde la perspectiva asumida por García Figueroa para dar cuenta del Derecho.

Lo que estoy tratando de decir es que creo que la distinción entre la «teoría de las fuentes» y la «teoría de la adjudicación», o entre creación y aplicación del Derecho, no resulta tan clara como García Figueroa parece suponer. En ocasiones la aplicación del Derecho, y la argumentación jurídica o el método jurídico, contribuyen a la conformación del Derecho, a la creación de normas jurídicas, y en este sentido deben ser incorporadas por una teoría de las fuentes que pretenda dar cuenta del origen de todas las normas que integran el Derecho. Creo que con un concepto de Derecho como el que subyace a este «positivismo» que García Figueroa pretende rescatar no es que únicamente se pueda dar cuenta del Derecho como un conjunto de normas generales (dejando al margen otras cosas que conforman el Derecho: valores, procedimientos...), sino que, como hemos visto, ni siquiera puede darse cuenta adecuadamente de todas esas normas; me refiero a aquéllas que no tengan su origen en autoridades ni sean el resultado de un proceso institucionalizado; estas normas no pueden verse, por tanto, como el producto del uso de reglas que confieren poderes.

\subsection{Los problemas «ideológicos»}

En opinión de García Figueroa, la mayoría de las confusiones conceptuales en las que incurriría la tesis del caso especial encontrarían su explicación en el hecho de que en ella se adopta un punto de vista interno para analizar el Derecho. Al adoptar este punto de vista, se abandonaría el terreno descriptivo pasando a situarse bien en un terreno claramente prescriptivo, o bien en el más ambiguo ámbito de la «reconstrucción». Este último merecería, para García Figueroa, ser doblemente criticado: por un lado, por no ser completamente descriptivo y, por otro lado, por la ambigüedad que genera respecto a su carácter. Los problemas derivados de ello son, en palabras de García Figueroa, «la legitimación acrítica del poder y la disolución de la moral crítica como instancia evaluadora del Derecho». Pero analicemos con algo más de detalle esta objeción. Creo que en su argumentación podemos encontrar dos problemas distintos, aunque relacionados, y que no conviene confundir. Por un lado, está el problema del punto de vista (interno o externo) adoptado por la teoría del Derecho; y, por otro lado, la cuestión de si la teoría presenta o no un carácter puramente descriptivo. Ambas cuestiones no son totalmente equiparables, porque se mueven en niveles distintos. La aceptación o adopción del punto de vista interno parece 
que ha de referirse necesariamente a algún determinado Derecho, mientras que se puede considerar que una teoría del Derecho no tiene un carácter puramente descriptivo sin que ello implique necesariamente la aceptación de ningún Derecho concreto. Así, podemos considerar que una buena teoría del Derecho no necesita aceptar ningún Derecho en particular, pero sostener al mismo tiempo que ha de ser «reconstructiva» con la práctica jurídica en general. Veamos por separado estas cuestiones.

\subsubsection{El punto de vista de la teoría}

En primer lugar, debemos preguntarnos qué alcance tiene la crítica de la adopción del punto de vista interno o del participante, qué quiere decir que la teoría «adopta el punto de vista del participante».

Hay que partir de que el Derecho es un fenómeno social y normativo. Como práctica social, su descripción requiere observación; si estamos interesados en dar cuenta de este fenómeno, entonces tendremos que observar a los participantes en dicha práctica que son quienes la conforman y determinan su contenido. El hecho de que se trate de un orden normativo implica que pretende guiar la conducta fundamentalmente a través de la aceptación de sus normas. De este modo, si la normatividad es un rasgo tan esencial del Derecho, entonces la teoría del Derecho tendrá necesariamente que fijar su atención en el aceptante. Pero esto no implica necesariamente que la teoría tiene que dejar de ser descriptiva. En palabras de Raz:

«Una teoría sobre la naturaleza del Derecho no debe ser una teoría justificatoria, si ello quiere decir una teoría que justifique alguna acción. Todo lo que debe hacer es explicar el Derecho. Pero para hacer esto debe explicar que los jueces y otras personas consideran el Derecho como justificatorio, y de qué forma lo consideran así, de qué forma está presente el Derecho en su razonamiento práctico. Debe hacerlo así porque es un rasgo esencial del Derecho el que éste pretenda ser una razón para la acción [...] Si una teoría jurídica [...] no toma en cuenta ese rasgo, o aún peor, si ofrece una imagen del Derecho que sea inconsistente con él, entonces esa teoría es defectuosa» ${ }^{12}$.

Para dar cuenta de este rasgo, de la normatividad del Derecho, habrá que preguntarse por qué consideran los aceptantes que el deber jurídico les obliga. En este punto la respuesta ha de ser necesariamente que obliga porque es aceptado, y será aceptado por el valor que se le atribuye. Podemos decir que este valor necesariamente ha de provenir o bien del valor que cabe atribuir a su origen (fundamentalmente las autoridades jurídicas) o bien del valor que cabe atribuir a su contenido (lo que la norma trata de proteger o promocionar). De este modo, los deberes jurídicos existen porque son acepta-

\footnotetext{
${ }^{12}$ En «Entrevista a Joseph Raz», Ruiz Manero, 1991, p. 331.
} 
dos y son aceptados bien porque provienen de aquéllos que se consideran que están legitimados para obligar (las autoridades legítimas), bien porque protegen y promocionan aquello que debe ser protegido y promocionado («el deber jurídico obliga porque se está sujeto a la autoridad, o porque ordena lo correcto»). La aceptación puede, por tanto, explicarse bien a partir de una u otra perspectiva, y aunque estos dos aspectos pueden aparecer en principio como compatibles, el problema se planteará cuando se presente algún conflicto entre ambos ${ }^{13}$. De nuevo es importante percatarse de que son elementos que pueden entrar en conflicto, para cuya superación habrá que primar uno de estos aspectos. Pero otorgar primacía a uno u otro es ya una cuestión valorativa y no meramente descriptiva.

Ahora bien, puede que lo que García Figueroa critique sea una implicación más fuerte de la teoría con el punto de vista interno. Se trataría entonces, no de que la teoría dé cuenta de la perspectiva interna, o del participante $^{14}$, en el análisis del Derecho, sino que la propia teoría «acepte» el Derecho, lo que, como acabamos de ver, se traduciría en aceptar o bien las autoridades o bien los valores de ese determinado Derecho. Así interpretado, quizás se pudiera estar de acuerdo con algunas de las observaciones de García Figueroa. Pero en este caso, todo su planteamiento habría de ser revisado, y creo que muchas de sus apreciaciones no se seguirían. Para empezar, la conexión que se produciría entre el razonamiento jurídico y el razonamiento práctico general ya no podría describirse, siguiendo los presupuestos de este mismo autor, como una conexión con la moral crítica sin más. Como hemos visto, este autor considera que, desde el punto de vista del aceptante, no se puede hablar de moral crítica, sino en todo caso de una «moral crítica social». Con ello, las diferencias entre la versión de la tesis del caso especial de la que García Figueroa se ocupa (y que sintetizaba del siguiente modo: «el razonamiento jurídico es un caso especial del razonamiento moral crítico») y la primera versión de esta misma tesis (que consi-

${ }^{13}$ Cfr. Aguiló, 2000, pp. 170 y ss. En un sentido similar, Ross hacía referencia a distintos motivos que podían influir en el juez a la hora de aceptar el Derecho (él hablaba de un respeto desinteresado frente al mismo); en particular hablaba de lo que denomina la conciencia jurídica formal y la material. Mientras que la primera consiste en respetar el Derecho por la concordancia de su contenido con ideas morales y de justicia; la segunda supone el respeto al Derecho por el mero hecho de ser Derecho, por ser el producto de ciertas instituciones independientemente de que sus prescripciones reflejen ideas de justicia aceptadas; y ambas concepciones de la conciencia jurídica, advierte Ross, pueden entrar en conflicto (Ross, 1970, pp. 133-134).

${ }^{14}$ Identificar sin más el punto de vista interno con el del participante puede resultar un tanto inapropiado, pero creo que para los objetivos de este trabajo pueden omitirse mayores precisiones. De todos modos, sobre esta cuestión puede verse Puppo, 1999. 
deraba que «el razonamiento jurídico es un caso especial del razonamiento moral social») se difuminarían mucho. Y aquí hemos de recordar que esta versión de la tesis del caso especial le parecía a García Figueroa aceptable.

\subsubsection{El carácter descriptivo de la teoría}

La segunda cuestión que antes hemos señalado tenía que ver con la crítica que se realiza a la teoría del Derecho suscrita por los partidarios de la tesis del caso especial por no tener un carácter puramente descriptivo.

A este respecto, lo que deberíamos plantearnos en primer lugar es si realmente el carácter puramente descriptivo de una teoría del Derecho es una ventaja de la misma, tal y como da por sentado García Figueroa, o si más bien implicaría algunas insuficiencias ${ }^{15}$. Antes hemos visto que el Derecho estaba caracterizado por algunos elementos que se encontraban en tensión entre sí; ahora bien, esta tensión es susceptible de ser descrita, pero las teorías del Derecho que pretenden presentar «la naturaleza» del Derecho como algo coherente y unívoco, lo que hacen es elegir un criterio de resolución de la tensión; esta resolución de la tensión -como veremos a continuación- ya no puede ser una mera descripción. Y son precisamente las teorías que optan por resolver estas tensiones, presentando la «naturaleza» del Derecho, las que en algún sentido participan en la práctica jurídica. Creo que resultaría bastante inútil una teoría del Derecho a la que se le negara la posibilidad de participar en la práctica jurídica ${ }^{16}$.

En segundo lugar, cabe preguntarse si la teoría del Derecho que subyace a las tesis de García Figueroa cumpliría realmente con su pretensión de pura descriptividad. Y, en mi opinión, la respuesta ha de ser negativa. En sus tesis podemos encontrar connotaciones ideológicas o valorativas, con lo cual estaría presente igualmente un aspecto prescriptivo o reconstructivo. Acabamos de recordar que en la práctica social en la que consiste el Derecho pueden encontrarse elementos en tensión, en particular hacíamos referencia a los elementos voluntaristas y a los racionalistas o justificativos. En este sentido, la adopción de una determinada perspectiva para dar cuenta del Derecho (la perspectiva del Derecho como orden jurídico, o como Derecho del caso) o la explicación de la normatividad del Derecho a partir de la aceptación de las autoridades (dando primacía a la idea de «sujeción») o de

${ }^{15}$ Esta sería, por ejemplo, la opinión de Aguiló, para quien «el coste tremendo que tiene limitarse a describir es que nunca se puede orientar. La orientación sólo es posible desde la 'participación': participar en una práctica social no es sólo reproducir la conducta en que consiste esa práctica, es también construirla» (Aguiló Regla, 2000, p. 193. La negrita es del autor)

${ }^{16}$ A este respecto véase Puppo, 1999, p. 236. 
la aceptación de los estados de cosas que se pretenden promocionar o proteger (dando primacía a la idea de lo «correcto») no pueden presentarse como una mera descripción. Si hay elementos en tensión, la resolución de esa tensión supone optar por uno de ellos ${ }^{17}$. Y la teoría del Derecho asumida por García Figueroa opta en estos dos casos. Opta por analizar el Derecho desde el punto de vista del legislador y opta por explicar la normatividad del fenómeno jurídico a partir de la idea de sujeción; en definitiva, opta por dar una clara primacía al elemento autoritativo o voluntarista sobre el elemento racionalista o justificativo del Derecho. Y esta opción no puede verse como correcta o incorrecta atendiendo a su adecuación al mundo, porque lo único que puede describirse es una práctica en la que encontramos elementos en tensión. Podría decirse que entre las dos concepciones del Derecho las divergencias no pueden describirse únicamente aludiendo a desacuerdos de creencias; lo que explicaría la existencia de tales desacuerdos sería la existencia entre ellas de un desacuerdo valorativo o de actitud. Mientras que el desacuerdo de creencias tiene que ver con la forma como las cosas han de ser fielmente descritas y explicadas, el desacuerdo de actitudes implica una oposición de propósitos, aspiraciones, necesidades, preferencias, deseos, etc. y tiene que ver con la forma como han de ser preferidas y, por ello, con la forma como han de ser conformadas por los esfuerzos humanos ${ }^{18}$. En nuestro caso, podemos considerar que la opción que resuelve las tensiones en el Derecho y que es la causa del desacuerdo de creencias entre las distintas concepciones rivales del Derecho viene determinada fundamentalmente por cuestiones de actitud, como podrían ser la confianza o desconfianza hacia la moral; y son precisamente estos desacuerdos valorativos los que generan los desacuerdos de creencia acerca de cómo ha de ser descrito el Derecho. Así, mientras que teorías del Derecho como la de la tesis del caso especial presentarían una actitud favorable frente a la moral, y considerarían que en determinados casos el método jurídico ha de incorporar al razonamiento moral; teorías como la de García Figueroa, mucho más escépticas frente al razonamiento moral, consideran que, en esos mismos casos, el método jurídico encuentra sus límites y ha de dar paso a la figura de la discrecionalidad.

\section{Conclusiones}

El principal problema de la concepción del Derecho que defiende García Figueroa radica, en mi opinión, en que la misma concibe al Derecho como un fenómeno «estático» o «cosificado»; no en el sentido de que no se

\footnotetext{
${ }^{17}$ Cfr. Aguiló, 2000, pp. 163 y ss.

${ }^{18}$ Cfr. Carrió, 1979, pp. 110 y ss.
} 
puede modificar en el tiempo, sino de que el Derecho es visto en cada momento como algo que existe ya acabado e independientemente de los procesos que dan lugar a su creación. Se trataría, por utilizar las palabras de Bayón al describir la visión de las reglas sociales que considera necesario evi$\operatorname{tar}^{19}$, de una visión del Derecho como algo reificado y con contornos precisos. Esta visión concuerda con la formulación de la tesis de las fuentes sociales del Derecho ofrecida por Raz, donde el Derecho es visto como un producto. Desde esa concepción, el Derecho es considerado como algo que puede ser completamente objetivado y observado sin ningún tipo de participación (puede ser casi «fotografiado»). De hecho, la propia distinción entre pertenencia y aplicabilidad, junto al predominio total dado a la noción de pertenencia parece avalar esta idea. Se «pertenece» a un conjunto, conjunto que por definición es presentado como algo cerrado, algo que existe de manera acabada. En mi opinión, ésta podría ser la explicación de por qué se excluyen los aspectos argumentativos de la teoría del Derecho y se consideran como fuentes del Derecho únicamente a las que pueden verse como derivadas de autoridades. Se trata de ver al Derecho como un orden jurídico compuesto por una serie de normas que quedan identificadas como tales acudiendo a una cadena de validez formal; en la que no habría lugar ni siquiera para establecer ciertos requisitos de validez material, pues la comprobación de éstos exigiría llevar a cabo actuaciones argumentativas.

Al desatender el aspecto dinámico del Derecho, el Derecho como proceso o, por decirlo en terminología de Alexy, el lado activo del Derecho, se olvida que un rasgo esencial de las prácticas sociales es precisamente que se encuentran permanentemente en construcción. Si tenemos en cuenta este dato, la «aplicabilidad» ya no puede ser algo secundario y residual, sino que cobra relevancia, pero eso sí, deja de poder ser explicada únicamente en términos de «pertenencia», entendida como validez meramente formal. Es precisamente la «aplicabilidad» lo que interesa a los que observan al Derecho como una técnica social de resolución de problemas, y no desde un enfoque científico, desde el cual el Derecho sería visto meramente como un objeto para ser estudiado ${ }^{20}$.

Para terminar señalaré que, si bien no sé si mis observaciones implican un abandono del «paradigma positivista», lo que sí creo es que las mismas serían compatibles al menos con las siguientes ideas positivistas: 1) El De-

\footnotetext{
${ }^{19}$ Aunque ésta objeción es presentada por Bayón respecto a la caracterización de una regla social, este mismo autor considera que sus observaciones resultan trasladables también para los sistemas jurídicos, puesto que éstos tienen su base en una regla social: la regla de reconocimiento (Bayón, 1991, pp. 713-721).

${ }^{20}$ Sobre esta diversidad de enfoque, cfr, Atienza, 2000.
} 
recho es una práctica social, y en este sentido es creado y modificado por actos humanos. Se trata de la tesis de las fuentes sociales del Derecho, sólo que añadiéndole una dimensión dinámica o activa; por volver con la formulación de Raz de esta tesis, creo que la misma debería ser reformulada, en el sentido de que el Derecho no puede ser visto únicamente como el «producto» de la práctica social, olvidando la dinámica que conforma dicha práctica (el «proceso»). 2) Una cosa es describir o dar cuenta de un determinado Derecho, y otra valorarlo moralmente «desde fuera». Pero, por un lado, esto es compatible con considerar que una adecuada explicación del contenido de un determinado Derecho exige observar al aceptante y operar con sus parámetros, lo que implica acudir a valores morales, sean aceptados o no por el teórico. Y, por otro lado, no prejuzga la idea de que quizás una teoría del Derecho «comprometida» con ciertos valores $-\mathrm{y}$ en este sentido no meramente descriptiva- pueda resultar socialmente más útil que una teoría «neutral».

\section{Bibliografía}

AGUILÓ REGLA, Josep (2000). Teoría general de las fuentes del Derecho (y del orden jurídico), Ariel, Barcelona.

ALEXY, Robert (1999): «La tesis del caso especial», trad. Isabel Lifante, Isegoría $\mathrm{n}^{\circ} 21$, pp. 23-35.

ATIENZA, Manuel (2000): El sentido del Derecho, Ariel, Barcelona (en prensa).

BAYÓN MOHÍNO, Juan Carlos (1991): La normatividad del Derecho, Centro de Estudios Constitucionales, Madrid.

BULYGIN, Eugenio (1991): «Tiempo y validez», en C. Alchourrón y E. Bulygin, Análisis lógico y Derecho, Centro de Estudios Constitucionales, Madrid, pp. 195-214.

CARRIÓ, Genaro R. (1979): Notas sobre Derecho y lenguaje, Abeledo Perrot, Buenos Aires, $2^{\mathrm{a}}$ edición.

GARCÍA FIGUEROA, Alfonso (1998): Principios y positivismo jurídico, Centro de Estudios Políticos y Constitucionales, Madrid.

GARCÍA FIGUEROA, Alfonso (1999): «La tesis del caso especial y el positivismo jurídico», Doxa n 22, pp. 195-220.

LIFANTE VIDAL, Isabel (1999.a): La interpretación jurídica en la teoría del Derecho contemporánea, Centro de Estudios Políticos y Constitucionales, Madrid.

LIFANTE VIDAL, Isabel (1999.b): «Interpretación y modelos de Derecho», Doxa no 22, pp. 171-193.

MORESO, José Juan (1997): La indeterminación del Derecho y la interpretación de la Constitución, Centro de Estudios Políticos y Constitucionales, Madrid.

PUPPO, Alberto (1999): «Los rostros de la ciencia jurídica entre aceptación, descripción e inscripción del Derecho», trad. Daniel González Lagier, en Doxa, $\mathrm{n}^{\circ}$ 22, 1999, pp. 233-261. 
ROSS, Alf (1970): Sobre el Derecho y la justicia, trad. de Genaro Carrió, Eudeba, Buenos Aires.

RUIZ MANERO, Juan (1991): «Entrevista a Joseph Raz», en Doxa, n 9, pp. 321344. 